\title{
Reactive Compatibilization of PLA/PA11 Blends and Their Application in Additive Manufacturing
}

\author{
Damien Rasselet, Anne-Sophie Caro-Bretelle, Aurélie Taguet and José-Marie Lopez-Cuesta *
}

IMT Mines Ales, C2MA, 6 avenue de Clavières, 30319 Alès CEDEX, France; damien.rasselet@mines-ales.fr (D.R.); anne-sophie.caro@mines-ales.fr (A.-S.C.-B.); aurelie.taguet@mines-ales.fr (A.T.)

* Correspondence: jose-marie.lopez-cuesta@mines-ales.fr; Tel.: +33-(0)4-6678-5334

Received: 17 December 2018; Accepted: 28 January 2019; Published: 5 February 2019

\begin{abstract}
The aim of this work was to study the properties of polylatic acid/polyamide 11 (PLA/PA11) blends compatibilized with a multifunctionalized epoxide, Joncryl ${ }^{\circledR}$, and to evaluate the performance of such blends processed by Fused Deposition Modeling (FDM) 3D printing, compared to those produced by injection molding method. Blends containing different Joncryl contents from 0.5 to $3 \mathrm{wt} \%$ were prepared by twin-screw extrusion. Evaluation of thermal, rheological and mechanical properties of such blends proved that Joncryl acted as a compatibilizer. Results showed that Joncryl effects on blends properties were improved with increasing its content. A significant reduction of PA11 dispersed phases diameter and an improvement of tensile properties with a ductile behavior were achieved for the highest Joncryl contents. A significant elongation of PA11 dispersed phases was observed into FDM filaments and dog bone shaped specimens produced thereafter. Despite this peculiar morphology, FDM printed samples exhibited only enhanced stiffness but poor reinforcement and elongation at break in comparison with injected ones.
\end{abstract}

Keywords: PLA; PA11; polymer blends; compatibilization; additive manufacturing

\section{Introduction}

Polylactic acid (PLA) is one of the bio-based polymers that generate the most interest, because of its biodegradability, high tensile strength and modulus. Nevertheless, its relatively poor thermal stability and significant brittleness may be major drawbacks for other large-scale commercial applications than packaging. To overcome these drawbacks, the most used and studied methods consist of adding nanoscaled mineral fillers (nanoparticles) to get a PLA-based nanocomposite or blending PLA with other polymers, bio-based as well as oil-based [1-9]. The latter strategy has been widely studied for PLA, because polymer blending is an efficient method commonly used at industrial scale, allowing properties of different polymers to be combined in order to obtain a new material with desirable properties. To achieve this objective, compatibilization is often required to improve polymer compatibility and control morphology.

In this context, polylactic acid/polyamide 11 (PLA/PA11) blends represent a good solution to get materials with improved thermomechanical properties compared to the ones of neat PLA. Indeed, polyamide 11 (PA11) is a bio-based polymer derived from castor oil with excellent thermal stability and high elongation at break and impact strength. Moreover, interfacial interactions and reactions, better known as interchange reactions, could potentially occur between polyamides and polyesters during melt blending, leading to an improvement of compatibility [10-15]. Hence, PA11 has been recently considered as a good candidate for blending with PLA.

Even if some studies have concluded to a partial compatibility with high interfacial interactions between PLA and PA11 [16-18], literature shows that the immiscibility and incompatibility of these polymers prevail, which makes compatibilization necessary. Various strategies were studied, most of 
them dealing with reactive pathways by adding catalyst $[17,19]$ to promote ester-amide interchange reactions, or reactive copolymer containing glycidyl methacrylate (GMA). Such copolymers are interesting, because GMA is a chemical moiety with epoxide functions, which can react with both hydroxyl and carboxyl reactive functional end chains of PLA and amine and carboxyl end groups of PA11. This coupling reaction at interface improves PLA/PA11 adhesion and compatibilizes the blend.

Dong et al. [20] have shown that ethylene glycidyl methacrylate-graft-styrene-co-acrylonitrile rubber (EGMA-g-AS) has no compatibilizing role in PLA/PA11 blends. Whatever the mixing sequence tested, EGMA-g-AS was never located at the interface and no decrease of the dispersed PA11 domains size was observed. Despite this, the development of a salami structure and the localization of EGMA-g-AS in PLA matrix led to better mechanical properties, with a large increase of ductility and impact strength, compared to the ones of neat blend.

Walha et al. [21] investigated the effects of incorporation of Joncryl ${ }^{\circledR}$ on the rheological, morphological and mechanical properties of PLA/PA11 blends. Joncryl ${ }^{\circledR}$ is a styrene-acrylic multifunctional epoxy copolymer, usually employed as chain extender to enhance polyesters thermal stability. Two main methods of mixing were used: the first one consisted of introducing all compounds simultaneously in the extruder and the second one consisted of modifying PLA by premixing it with Joncryl and then adding PA11. Authors demonstrated the role of Joncryl as a compatibilizer for the PLA/PA11 system, by the significant decrease of the size of PA11 dispersed phases and the interfacial tension as well as the improvement of ductility, especially with the second mixing route. Similar results were obtained by Zolali et al. [22], that used ethylene methyl acrylate-glycidyl methacrylate to compatibilize a co-continuous PLA/PA11 blend.

The aim of this work was to study the properties of PLA/PA11 blends compatibilized with a multifunctionalized epoxide, Joncryl ${ }^{\circledR}$. Compared to Walha et al., our works were dedicated to optimize mechanical properties of a PLA/PA11 80/20 wt $\%$ blend with an extended range of Joncryl percentage, and to determine the effects of Joncryl on blends morphology and properties.

The second objective was to evaluate the performance of such blends processed by Fused Deposition Modeling (FDM) 3D printing, compared to those produced by injection molding method. To the best of our knowledge, this is the first study addressing the application of PLA/PA11 blend for 3D printing, especially FDM. Additive manufacturing or 3D printing recently gained an increasing interest in industry as well as academic area. Additive manufacturing gathers a lot of processing techniques, having the ability to produce complex geometries pieces layer by layer with low cost production, and exhibiting numerous advantages associated with rapid prototyping. But up to now, few compatible materials with 3D printing are available on the market, restricting its tremendous potential. PLA is one of the most used polymers for this technology, and PLA based blends are a good solution to develop materials with specific required properties and to expand the range of 3D printable materials [23-28].

In the first part, the morphology of blends with different Joncryl contents will be examined to assess the effectiveness of Joncryl as compatibilizing agent. Then, the effects of Joncryl on thermal and rheological properties will be evaluated. In the second part, a study of the influence of FDM process on the morphology and mechanical properties obtained for compatibilized blends, compared to the ones obtained for injected samples, will be performed.

\section{Materials and Methods}

\subsection{Materials}

The polylactide (PLA grade 3251D) used in this study was purchased from NatureWorks (Minnetonka, MN, USA). It is a semi-crystalline grade. The polyamide 11 (PA11 grade LMFO) was produced by Arkema (Colombes, France) under the trade name Rilsan ${ }^{\circledR}$. A commercially available modified acrylic copolymer with epoxy functions (Joncryl ADR ${ }^{\circledR}-4368$ ) was obtained from BASF (Ludwigshafen, Germany). It has an epoxy equivalent weight of $285 \mathrm{~g} / \mathrm{mol}$, an average functionality 
on epoxide of 9 and a weight-average molecular weight $\mathrm{Mw}$ of $6800 \mathrm{~g} / \mathrm{mol}$. Its chemical structure is depicted in Figure 1. Table 1 shows some properties of the used materials.

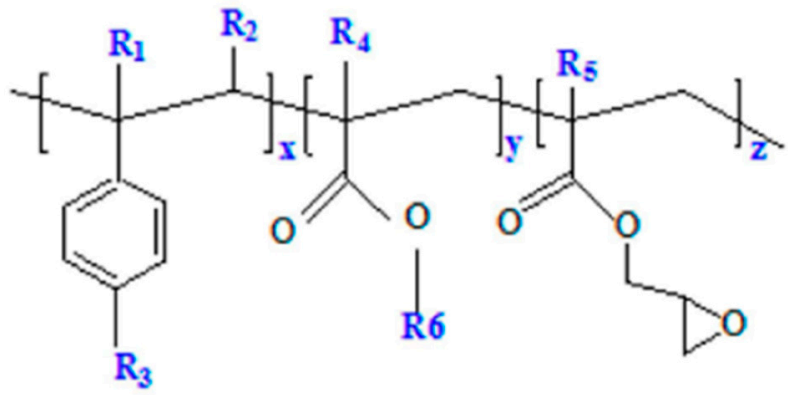

Figure 1. Chemical structure of Joncryl $\mathrm{ADR}^{\circledR}-4368$, and the general structure of the styrene-acrylic multifunctional oligomeric chain extenders. $\mathrm{R}_{1}-\mathrm{R}_{5}$ are $\mathrm{H}, \mathrm{CH}_{3}$, a higher alkyl group or combinations of them; $R_{6}$ is an alkyl group. $x, y$ and $z$ are between 1 and 20 .

Table 1. Characteristics of the raw materials.

\begin{tabular}{ccccc}
\hline Material & Density $\left(\mathrm{g} / \mathrm{cm}^{3}\right)$ & $\mathbf{T}_{\mathrm{g}}\left({ }^{\circ} \mathrm{C}\right)$ & $\mathbf{T}_{\mathbf{c c}}\left({ }^{\circ} \mathrm{C}\right)$ & $\mathbf{T}_{\mathbf{m}}\left({ }^{\circ} \mathbf{C}\right)$ \\
\hline PLA & 1.24 & $59 *$ & $101^{*}$ & $170^{*}$ \\
PA11 & 1.02 & - & - & $190^{*}$ \\
Joncryl & 1.08 & 54 & - & - \\
\hline \multicolumn{4}{r}{ * From Differential Scanning Calorimetry (DSC) experimental data. }
\end{tabular}

\subsection{Blend Preparation}

Before extrusion, PLA and PA11 pellets were dried under vacuum at $80^{\circ} \mathrm{C}$ overnight (and Joncryl $15 \mathrm{~min}$ ). Then, the blends were prepared in a co-rotating twin screw extruder (BC21, Clextral, Firminy, France), with a screw diameter of $25 \mathrm{~mm}$ and an L/D ratio of 48. A vacuum pump (Sterling Fluid Systems, Manchester, UK) was used to avoid oxidation and hydrolytic degradation during extrusion. The extrusion temperature profile was $80^{\circ} \mathrm{C}$ for the feed zone, and $210{ }^{\circ} \mathrm{C}$ for all the other zones and the die. A feeding rate of $4 \mathrm{~kg} / \mathrm{h}$ and a $200 \mathrm{rpm}$ screw speed were applied.

Blends were prepared into two steps. First, PLA and $4 \mathrm{wt} \%$ Joncryl were mixed together in the twin-screw extruder, quenched in cold water and granulated. Then, modified PLA (named PLA-J4) pellets were dried under vacuum at $80{ }^{\circ} \mathrm{C}$ overnight, and secondary mixed by twin-screw extrusion with PA11 and virgin PLA. Through this way, PLA/PA11 80/20 wt/wt blends containing 0 to $3 \mathrm{wt} \%$ of Joncryl, based in total weight of polymer blend, (named PLA80-J0 to J3) were prepared. PLA-J4 was prepared as a masterbatch, in order to get (by dilution) high Joncryl contents in final blends named PLA80-Jx ( $x$ as Joncryl content, with $x \leq 3$ ). Total residence time in extruder was 3 min for all blends.

At the outlet of twin-screw extruder, blends were obtained as extruded threads, that were quenched in cold water and granulated to get pellets, used thereafter to produce samples.

\subsection{Standard Samples Preparation}

Before samples preparation by injection molding or 3D printing, prepared blends pellets were dried under vacuum at $80{ }^{\circ} \mathrm{C}$ overnight. A part of obtained pellets were molded using a mini injection molding machine (ZAMAK Mercator, Swakina, Poland) into dog bone shaped samples (ISO 527-2:2012, 1BA standard type) for tensile test. The following parameters were used: Mold temperature $=80^{\circ} \mathrm{C}$, Barrel temperature $=210{ }^{\circ} \mathrm{C}$, Injection pressure $=5.2$ bars, Melting time of pellets before injection $=3 \mathrm{~min}$.

The remaining fraction of pellets were first extruded using a single screw extruder (Yvroud, Ingre, France) at a temperature of $210{ }^{\circ} \mathrm{C}$ and a flow rate of $7 \mathrm{~m} / \mathrm{min}$, to get filaments with a diameter of $2.50 \pm 0.1 \mathrm{~mm}$. These filaments were then fed into a Fused Deposition Modeling (FDM) printer (A4v3, 
3ntr, Oleggio, Novare, Italy) to produce samples with the same dimensions as those produced via injection molding. Printing was performed at $210^{\circ} \mathrm{C}$ and a flow rate of $65 \mathrm{~mm} / \mathrm{s}$. Melted filaments were deposited with $\mathrm{a}+/-45^{\circ}$ angle on a plate support heated at $60^{\circ} \mathrm{C}$.

\subsection{Morphological Characterizations}

\subsubsection{Scanning Electron Microscopy (SEM)}

A Scanning Electron Microscopy Quanta 200 FEG (FEI, Hillsboro, OR, USA) was used to observe blends morphology. The samples were fractured in liquid nitrogen, and fracture surfaces were coated with carbon. All the micrographs were recorded under high vacuum at an accelerating voltage of $3 \mathrm{kV}$.

\subsubsection{Selective Extraction}

For each composition, $900 \mathrm{mg}$ of extruded thread were immersed into $15 \mathrm{~mL}$ of chloroform at room temperature with stirring during $48 \mathrm{~h}$ to remove PLA. Then, PA11 nodules were purified by three washing/centrifugation cycles (10,000 rpm, $5 \mathrm{~min})$ using chloroform and finally collected for analysis.

\subsubsection{Laser Diffraction Particle Size Analyzer}

A Coulter LS 13230 (Beckman Coulter, Brea, CA, USA) laser diffraction particle size analyzer instrument was used to determine the size distribution of extracted PA11 nodules. Size measurements were performed using the micro liquid module $(15 \mathrm{~mL})$ in chloroform; obscuration was $10 \pm 2 \%$. Three measurements were performed for each sample.

Laser diffraction particle size analyzer is an interesting alternative method to characterize dispersed phases in immiscible polymer blends. In fact, the number of dispersed phases analyzed is much larger than with conventional images analysis from electron microscopy observations (SEM or TEM (Transmission Electron Microscopy)).

\subsection{Differential Scanning Calorimetry (DSC)}

A Pyris Diamond DSC (PerkinElmer Instruments, Waltham, MA, USA) differential scanning calorimeter was used to measure the thermal characteristics of the blends. Samples of around $15 \mathrm{mg}$ were cut from the pellets and put in $50 \mu \mathrm{L}$ sealed aluminum pans. All the experiments were performed under dry nitrogen as a protective gas $(20 \mathrm{~mL} / \mathrm{min})$. Three calorimetric scans were performed for each sample at a heating or cooling rate of $10^{\circ} \mathrm{C} / \mathrm{min}$. The first heating scan, in which the thermal history was suppressed, was performed from $30^{\circ} \mathrm{C}$ to $220^{\circ} \mathrm{C}$ before a 2 min isothermal scan at $220^{\circ} \mathrm{C}$ was applied. Then, the cooling scan went from $220^{\circ} \mathrm{C}$ to $30^{\circ} \mathrm{C}$, before a 2 min isothermal scan at $30^{\circ} \mathrm{C}$ was applied, and finally the second heating scan was performed from $0{ }^{\circ} \mathrm{C}$ to $220^{\circ} \mathrm{C}$.

The thermal characteristics-glass transition temperature $\left(\mathrm{T}_{\mathrm{g}}\right)$, cold crystallization temperature $\left(\mathrm{T}_{\mathrm{cc}}\right)$, enthalpy of cold crystallization $\left(\Delta \mathrm{H}_{\mathrm{cc}}\right)$, melting temperature $\left(\mathrm{T}_{\mathrm{m}}\right)$ and melting enthalpy $\left(\Delta \mathrm{H}_{\mathrm{m}}\right)$-were determined from the second heating scan. The degree of crystallinity $\left(\mathrm{X}_{\mathrm{C}}\right)$ of the PLA and PA11 into the blend were calculated using the following equation:

$$
\mathrm{X}_{\mathrm{c}}=\frac{\triangle \mathrm{H}_{\mathrm{m}}-\triangle \mathrm{H}_{\mathrm{cc}}}{\triangle \mathrm{H}_{\mathrm{m}}^{0} \times \mathrm{w}} \times 100,
$$

$\Delta \mathrm{H}_{\mathrm{m}}{ }^{0}$ is the enthalpy of fusion per mole of repeating unit of perfect crystal of infinite size (totally crystalline polymer). We considered $\Delta \mathrm{H}_{\mathrm{m}}{ }^{0}(\mathrm{PLA})=93 \mathrm{~J} / \mathrm{g}$ [29] and $\Delta \mathrm{H}_{\mathrm{m}}{ }^{0}(\mathrm{PA} 11)=200 \mathrm{~J} / \mathrm{g}$ [30]). $\mathrm{w}$ is the weight fraction of polymer into the blend.

At least two measurements were performed for each sample. 


\subsection{Rheological Tests}

All samples were prepared using a mini injection molding machine (ZAMAK Mercator, Swakina, Poland) at $210{ }^{\circ} \mathrm{C}$ for $3 \mathrm{~min}$ with a constant pressure of 5.2 bars in the form of disks of $25 \mathrm{~mm}$ diameter and $1.5 \mathrm{~mm}$ thickness. All samples were dried in a vacuum oven at $80^{\circ} \mathrm{C}$ for $24 \mathrm{~h}$ before the rheological tests.

The rheological analysis was carried out using a controlled-stress rheometer (MCR 702 TwinDrive, Anton Paar, Graz, Austria) in a parallel plate geometry ( $25 \mathrm{~mm}$ diameter) and a $1.3 \mathrm{~mm}$ gap at $210{ }^{\circ} \mathrm{C}$ under dry nitrogen flow. The linear viscoelastic region was determined using strain sweep tests for the neat polymers at $6.28 \mathrm{rad} / \mathrm{s}$ frequency. According to the obtained results, the frequency sweep tests were performed at a strain of $2 \%$, from 100 to $0.01 \mathrm{rad} / \mathrm{s}$. The stability of samples under the test conditions was checked using a time sweep test and a less than $7 \%$ drop in the complex viscosity was observed in the experimental time scale of $60 \mathrm{~min}$.

\subsection{Tensile Tests}

Tensile properties were obtained using a universal tensile machine Zwick Z010 (Zwick Roell, Ulm, Germany). For each composition, at least five dog bone shaped samples (ISO 527-2:2012 type 1BA standard), prepared by injection molding or FDM as described previously, were tested in ambient conditions (around $23{ }^{\circ} \mathrm{C}$ and $50 \%$ relative humidity).

Tensile tests were performed first at a cross-head speed of $5 \mathrm{~mm} / \mathrm{min}$ to determine Young modulus (E), then at $100 \mathrm{~mm} / \mathrm{min}$ until material failed. Maximum stress $\left(\sigma_{\mathrm{m}}\right)$, elongation at break $\left(\varepsilon_{\mathrm{b}}\right)$ and stress at break $\left(\sigma_{\mathrm{b}}\right)$ were recorded.

\subsection{Porosity Measurement}

Porosity, defined by the ratio of voids volume $\left(\mathrm{V}_{\text {voids }}\right)$ to total volume $\left(\mathrm{V}_{\text {total }}\right)$, of FDM printed samples was determined to judge their intrinsic brittleness with the following equation:

$$
\operatorname{Porosity}(\%)=\frac{\mathrm{V}_{\text {voids }}}{\mathrm{V}_{\text {total }}}=\left[1-\frac{\mathrm{d}_{\text {apparent }}}{\mathrm{d}_{\text {absolute }}}\right] \times 100,
$$

where $\mathrm{d}$ refers to density, apparent or absolute.

Apparent density is defined as the ratio between the global mass and the global volume of a material, as it appears including pores. Global mass was measured by weighing samples (complete dog bone shaped samples) and volume was determined measuring exact dimensions samples with a vernier caliper.

Absolute density refers to the real density of a material, which means the ratio between the global mass and the solid volume of a material excluding pores. This density was determined using an helium pycnometer (Accu Py 1330, Micromeritics, Norcross, GA, USA).

Two samples by composition were used for these measurements.

\section{Results and Discussion}

\subsection{Effects of Joncryl on Blends Morphology and Properties}

\subsubsection{Blends Morphology}

Figure 2 shows SEM images of PLA/PA11 blends prepared by melt extrusion. As expected, all blends exhibit sea island morphology, with a PLA matrix and PA11 dispersed droplets. We can note that PA11 dispersed phases diameter seems to decrease with increasing Joncryl content. For Joncryl content higher than $1.0 \mathrm{wt} \%$, no significant evolution could be observed. 




Figure 2. SEM observations of extruded samples threads in transversal direction.

To confirm this trend, size distribution and average diameter of extracted PA11 nodules, after PLA dissolution by chloroform, were determined using laser diffraction analysis. As we can see on Figure 3, a reduction of PA11 dispersed phases volume diameter with increasing Joncryl content is well observed. Joncryl addition leads to submicronic nodules (Table S1). Compared to neat blend, we can also note a narrowing of the size distribution with Joncryl addition, which is in good correlation with SEM observations.

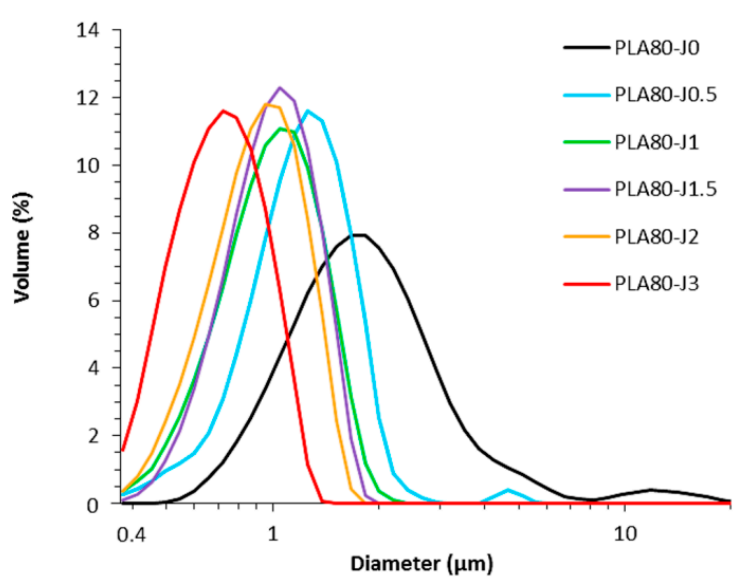

(a)

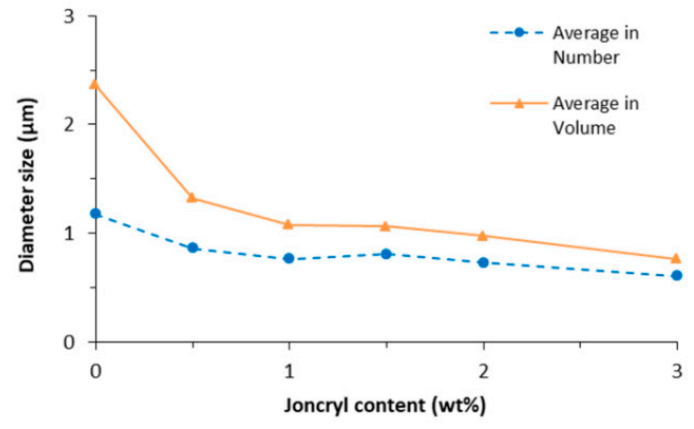

(b)

Figure 3. Size distribution curves (a) and emulsification curve (b) of PA11 dispersed phases diameter as a function of Joncryl content.

The observed PA11 diameter reduction shows that Joncryl has an emulsifying effect on the blend, because of coalescence suppression. Such phenomenon could be associated with compatibilization due to the chemical reactivity of the epoxide function of Joncryl with the polymers of the blend, i.e., amine and acid chain end of PA11 and PLA, respectively, as concluded by Walha et al. [21]. Moreover, regarding the emulsification curve, a saturation of the reaction at the interface occurs around $1.0 \mathrm{wt} \%$ of Joncryl. 


\subsubsection{Thermal Properties and Crystallinity}

DSC thermograms and data collected from the second heating scan of neat polymers (PLA, PLA-J4 and PA11) and their blends PLA80-Jx with various Joncryl content $(x)$ are presented in Figure 4 and Table 2.

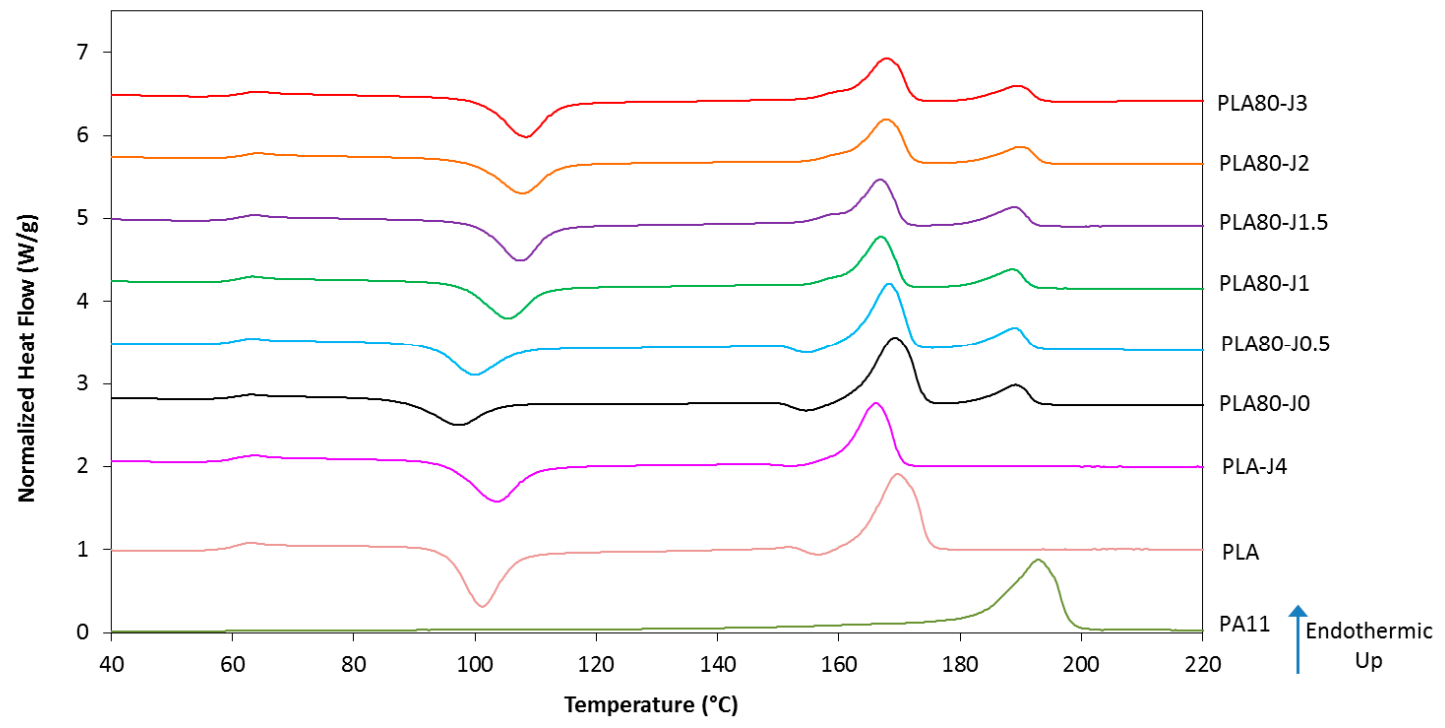

(a)



(b)

Figure 4. DSC thermograms of the second heating of neat polymers (a) and PLA80-Jx blends (b).

The addition of PA11 to the PLA (PLA80-J0) dramatically increases the PLA crystallinity degree $\left(X_{c}\right)$. PA11 domains might act as nucleating centers and thereby enhance the crystallization of the PLA in the blend [31]. For compatibilized blends, the higher the Joncryl content, the higher the PLA cold crystallization temperature $\mathrm{T}_{\mathrm{cc}}$ in the blend. Thus, $\mathrm{T}_{\mathrm{cc}}$ is shifted from $98{ }^{\circ} \mathrm{C}$ (neat blend) to $109{ }^{\circ} \mathrm{C}$ (PLA80-J3), which represents an increase of $11^{\circ} \mathrm{C}$. At the same time, a slight increase of $\Delta \mathrm{H}_{\mathrm{cc}}$ is observed. For Joncryl content higher than $0.5 \mathrm{wt} \%$, we can also note the disappearance of the second PLA cold crystallization peak. Finally, PLA crystallinity degree drops with increasing Joncryl content from $22.4 \%$ to $1.6 \%$. Similar changes can be noted if PLA-J4 data are compared with pure PLA data. 
Table 2. DSC results obtained from the second heating scan.

\begin{tabular}{|c|c|c|c|c|c|c|c|c|c|c|c|}
\hline Samples & $\begin{array}{l}T_{g} \\
\text { PLA } \\
\left({ }^{\circ} \mathrm{C}\right)\end{array}$ & $\begin{array}{l}T_{\text {cc }} \\
\text { PLA } \\
\left({ }^{\circ} \mathrm{C}\right)\end{array}$ & $\begin{array}{l}\Delta \mathrm{H}_{\mathrm{cc}} \\
\mathrm{PLA} \\
(\mathrm{J} / \mathrm{g})\end{array}$ & $\begin{array}{l}T_{\mathrm{cc} 2} \\
\text { PLA } \\
\left({ }^{\circ} \mathrm{C}\right)\end{array}$ & $\begin{array}{c}\Delta \mathrm{H}_{\mathrm{cc} 2} \\
\mathbf{P L A} \\
(\mathrm{J} / \mathrm{g})\end{array}$ & $\begin{array}{l}\mathrm{T}_{\mathrm{m}} \\
\text { PLA } \\
\left({ }^{\circ} \mathrm{C}\right)\end{array}$ & $\begin{array}{l}\Delta H_{m} \\
P L A \\
(J / g)\end{array}$ & $\begin{array}{c}T_{m} \\
\text { PA11 } \\
\left({ }^{\circ} \mathrm{C}\right)\end{array}$ & $\begin{array}{c}\Delta H_{\mathrm{m}} \\
\text { PA11 } \\
\text { (J/g) }\end{array}$ & $\begin{array}{c}X_{c} \\
\text { PLA } \\
(\%)\end{array}$ & $\begin{array}{c}X_{c} \\
\text { PA11 } \\
(\%)\end{array}$ \\
\hline PLA & 59 & 101 & 32.7 & 156 & 1.6 & 170 & 40.4 & - & - & 6.9 & - \\
\hline PLA-J4 & 59 & 104 & 26.3 & 152 & 0.4 & 166 & 30.6 & - & - & 4.3 & - \\
\hline PA11 & - & - & - & - & - & - & - & 193 & 49.2 & - & 24.6 \\
\hline PLA80-J0 & 60 & 98 & 18.0 & 155 & 2.6 & 170 & 34.7 & 190 & 8.9 & 22.4 & 22.2 \\
\hline PLA80-J0.5 & 60 & 101 & 21.7 & 155 & 1.6 & 169 & 29.9 & 190 & 9.4 & 11.0 & 23.6 \\
\hline PLA80-J1 & 60 & 106 & 21.7 & - & - & 168 & 24.4 & 189 & 9.1 & 3.6 & 23.0 \\
\hline PLA80-J1.5 & 60 & 107 & 22.4 & - & - & 167 & 23.5 & 189 & 9.4 & 1.6 & 23.8 \\
\hline PLA80-J2 & 61 & 108 & 21.7 & - & - & 168 & 23.6 & 190 & 8.9 & 2.6 & 22.7 \\
\hline PLA80-J3 & 60 & 109 & 22.8 & - & - & 168 & 23.9 & 189 & 8.2 & 1.6 & 21.2 \\
\hline
\end{tabular}

It shows that the observed crystallization modifications are related to structural modification of PLA chains induced by Joncryl. As a chain extender, Joncryl leads to increase length chains and their molecular weight. Hence, long-chain branched structures are formed in Joncryl-modified PLA that increase molecular weight and decrease chains mobility [32]. The presence of branches disrupts the packing of polymer chains, thus preventing crystallization happening during the cooling step. As a consequence, crystallinity degree decreases. The reduced chain mobility is responsible for the increased cold crystallization temperature, as observed by Najafi et al. [33].

Hence, it can be considered that the same behavior also occurs in blends, its intensity being governed by the PLA-J4 amount. No significant change concerning glass transition and melting temperatures of each polymer into blends was observed.

\subsubsection{Rheological Behavior}

Figure 5 illustrates the evolution of the complex viscosity $\eta^{*}$, the storage modulus $G^{\prime}$ and the loss modulus G" versus angular frequency of PLA, PLA-J4, PA11 and PLA80-Jx blends (for x = 0; 0.5; $1.5 ; 3)$. First, we can note that PLA-J4 has a lower complex viscosity than PLA, but with a crossover point (between $G^{\prime}$ and $G^{\prime \prime}$ ) occurring at lower frequency than PLA. These results might be explained by the fact that some PLA chains have reacted with Joncryl, increasing the molecular weight or chain branching and then increasing the relaxation time of the chain [34]. Indeed, Wang et al. [35] have observed a slight crosslinking and an increase in molecular weight of PLA in the presence of Joncryl. However, in the other hand, there is probably free Joncryl that has not reacted with any PLA chains, because it was introduced in excess, and, as Joncryl is a small molecule $\left(\eta_{0}=30.6 \mathrm{~Pa} \cdot \mathrm{s}\right)$, it dramatically contributes to decrease the viscosity of the whole PLA-J4 sample.

The complex viscosity curve of the neat PLA/PA11 blend is located between the values obtained for the neat polymers. When PLA-J4 is added, complex viscosity is increased with increasing Joncryl content in the blend over the whole frequency range. This result is in accordance with Walha et al. works [21]. These authors showed that such behavior can be associated with chemical reaction taking place between PLA and PA11 and indicates an increase of the intermolecular interactions of the blend system due to this interfacial reaction. A narrowing of the Newtonian plateau at low frequency is also observed. It must be noticed that, at low frequency, PLA80-J3 exhibit a yield behavior compared to the other PLA80-Jx formulations. This yield behavior is identified on the shape of $\eta^{*}$ at low frequency that does not reach a plateau and on the behavior of $G^{\prime}$ which tends to reach a plateau value at low frequency. These behaviors are often reported in reactive compatibilization [36-38].

Moreover, PLA80-J3complex viscosity is slightly lower than that of PLA80-J1.5. We can assume that, between 1.5 and $3 \mathrm{wt} \%$ Joncryl, both amine and acid chain end of PA11 and PLA have completely reacted. The saturation is attained and the excess of Joncryl that didn't react contributes to decrease the complex viscosity. In the same way as PLA-J4, an excess of Joncryl decreases the complex viscosity of the blend PLA80-J3. 


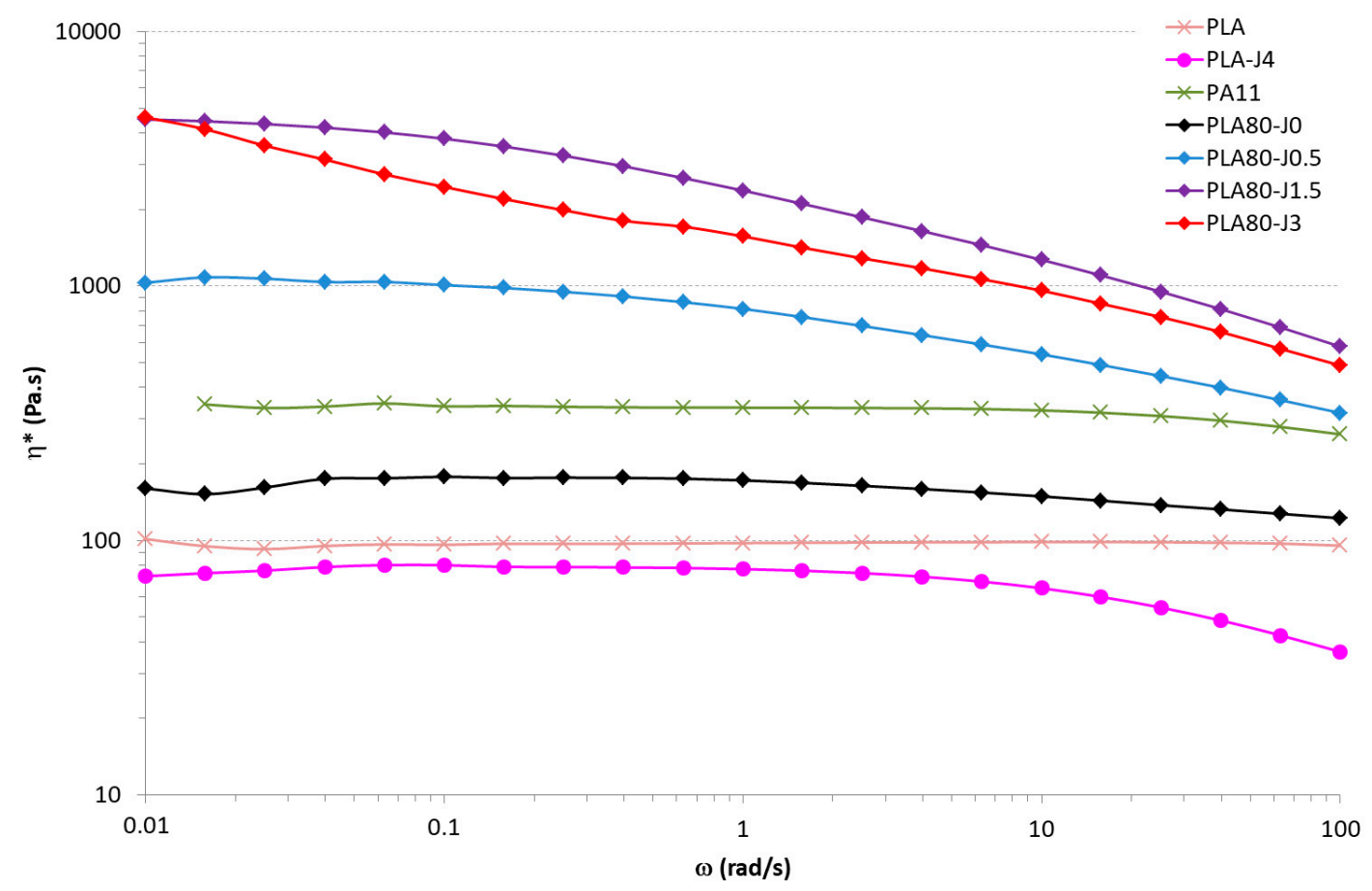

(a)

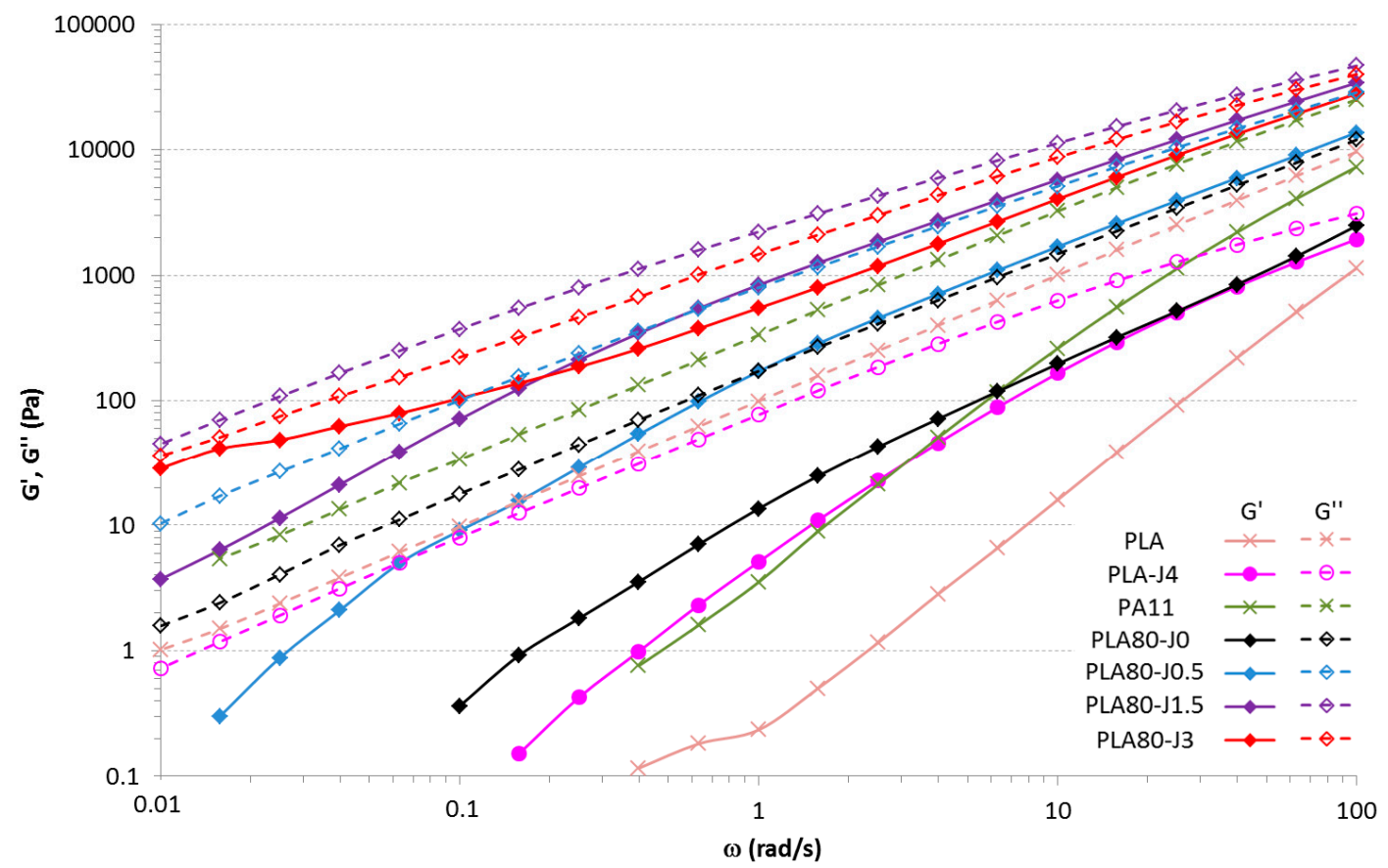

(b)

Figure 5. Complex viscosity (a), storage modulus (full lines) and loss modulus (dashed lines) (b) versus the angular frequency for PLA, PLA-J4 and PA11 PLA80-Jx blends $(x=0 ; 0.5 ; 1.5 ; 3)$.

$\mathrm{G}^{\prime}$ of the neat blend is in between that of the pure polymers from 100 to $10 \mathrm{rad} / \mathrm{s}$, then it diverges from the rule of mixture as $G^{\prime}$ of the PLA80 blend become higher than $G^{\prime}$ of the PA11 at lower frequency. This is due to the well-known shape relaxation behavior [39]. G' of PLA80-Jx samples raises with 
increasing Joncryl content, because of the appearance of some extended/branched chains as well as an increase of the entanglement density.

\subsection{Comparison Between Injected and FDM Samples Morphology and Mechanical Properties}

\subsubsection{FDM Filaments and Dog Bone Shaped Samples Morphology}

SEM observations of cross-sections of FDM filaments prepared by single-screw Yvroud extrusion are shown in Figure 6. They can be compared with Figure S1, depicting SEM micrographs of cross-sections corresponding to the extrusion direction (longitudinal) performed on extruded threads obtained by twin-screw extrusion.



Figure 6. SEM observations of FDM filaments in longitudinal direction.

For both extruded threads and FDM filaments, a reduction of PA11 dispersed phase diameters with increasing Joncryl content is observed, similarly to the previous observations about transverse cross-sections (Figure 2). Elongated PA11 nodules are observed for a Joncryl content between 1 and $3 \mathrm{wt} \%$ in FDM filaments. Moreover, we can note that the higher the Joncryl content, the more important the number and length of elongated phases, except for PLA80-J3.

It can be considered that the presence of elongated phases results from a decrease of the interfacial tension, due to the compatibilizing role of the agent Joncryl. But, it could also be the result of a change in viscosity ratio, that affects the droplets coalescence and breakup mechanisms which governs the morphology of the polymer blend $[40,41]$. Indeed, if the matrix viscosity decreases, the viscosity ratio, defined as the ratio between dispersed phase viscosity and the matrix one's, increases. In our case, it was shown previously that from $1.5 \mathrm{wt} \%$ of Joncryl in the blend, the viscosity starts to decrease. Hence from $1.5 \mathrm{wt} \%$ of Joncryl, the polymer matrix is composed of PLA and unreacted Joncryl, and the blend viscosity is decreased. This promotes PA11 elongation by impeding thread break-up.

Concerning PLA80-J2 blend, the aspect ratio of PA11 phases is more important for FDM filaments than for extruded threads. Supplementary elongation in FDM filament could be explained by the higher mechanical stresses applied during single-screw extrusion, compared to the ones applied during twin-screw extrusion to get extruded threads. 
For dog bone shaped samples, processed through 3D printing, elongated PA11 dispersed phases also appear for all compositions (Figure 7). Figure 7 shows that FDM process induces supplementary elongation, in addition to filament extrusion.

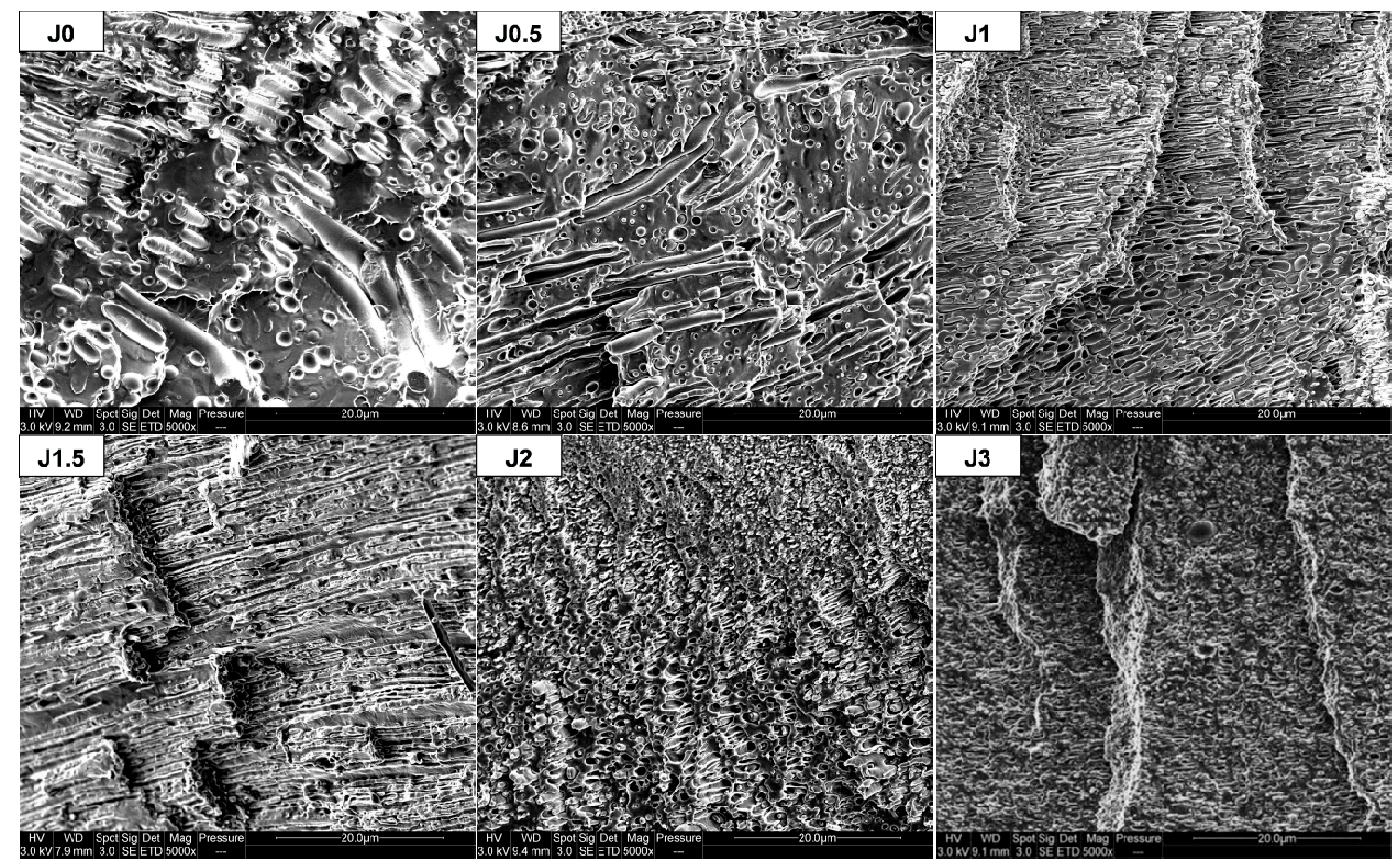

Figure 7. SEM observations of FDM dog bone shaped samples in longitudinal direction.

\subsubsection{Mechanical Properties}

The results of tensile properties after injection show that the brittle properties of PLA can be modified by the addition of Joncryl. The elongation at break is doubled, since it increases from $2.1 \%$ (pure PLA) to 4.3\% (PLA-J4), and maximal stress increases too. But, in contrast, adding ductile PA11 to brittle PLA does not improve significantly its mechanical properties, since PLA80-J0 blend shows a similar behavior than neat PLA (Figure 8a). That is certainly due to a lack of adhesion between polymers, because of their immiscibility and incompatibility.



(a)

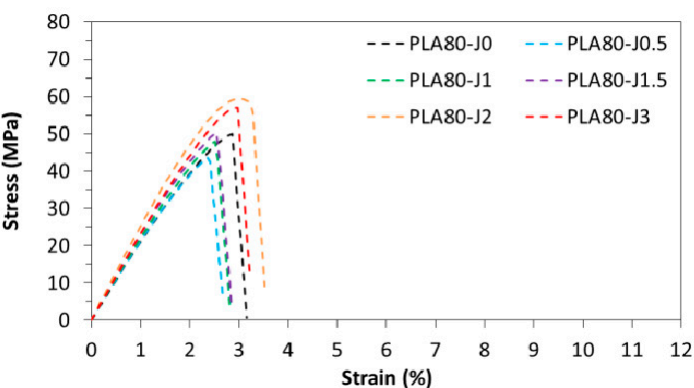

(b)

Figure 8. Stress-strain curves of injected PLA, PLA-J4 and PLA80-Jx blends (a) and FDM printed PLA80-Jx blends (b).

Blending PLA-J4 with PLA and PA11 entails an increase on elongation at break (after injection), which tends to increase with increasing Joncryl content. At high Joncryl content 2 and $3 \mathrm{wt} \%$, a ductile behavior is observed, with the highest elongation at break of $6.9 \%$ and $9.8 \%$ respectively (Figure $8 \mathrm{a}$, Table S2). No significant change of tensile modulus and maximal stress is noticed compared to the neat 
blend. Such behavior indicates that an improved interface between PLA and PA11 was established by reactive compatibilization with Joncryl. To confirm this conclusion, SEM observations of tensile fracture surface for injected samples were carried out.

In comparison with the neat blend, elongation of PA11 dispersed phases in the compatibilized blends was observed. After tensile test, this phenomenon is all the more important since Joncryl content is high and two cases can be distinguished (Figure 9):

- For $0 \leq \mathrm{x} \leq 1.5$ : PA11 dispersed phases extend individually but not PLA matrix, because of its intrinsic brittle behavior and owing to the lack of interfacial adhesion, leading to a clear brittle failure.

- For $x=2$ or 3: PA11 dispersed phases extend with PLA matrix and form an elongated structure, leading to a ductile failure.

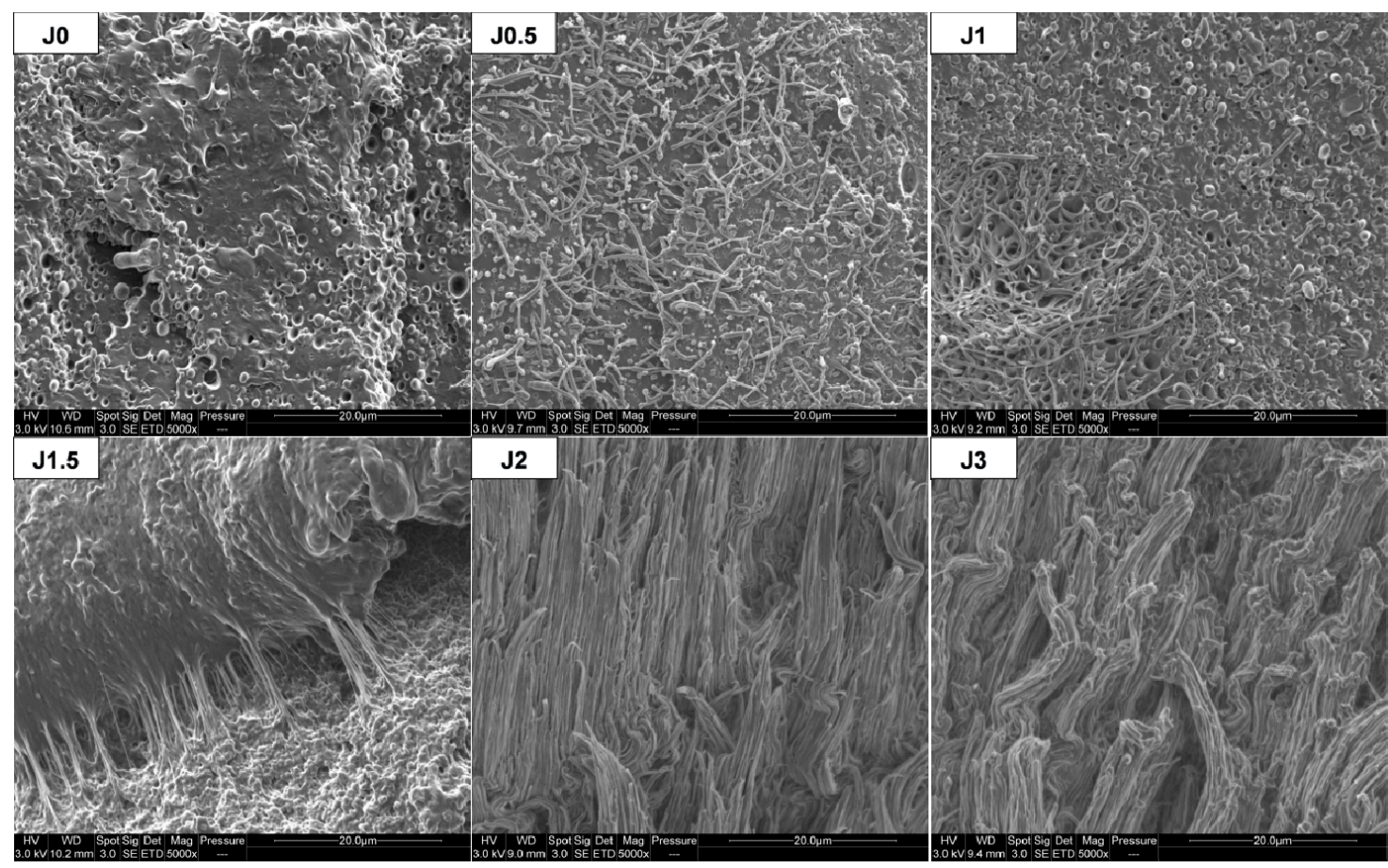

Figure 9. SEM observations of tensile fracture surface for injected PLA80-Jx.

Hence, thanks to a sufficient interfacial adhesion, PA11 dispersed phases could transfer mechanical stress, more easily at high Joncryl content, to enable a more ductile behavior.

PA11 dispersed phases size reduction could also contribute to increase elongation at break. Indeed, this phenomenon leads a better homogeneity of PA11 nodules into blend, as evidenced by SEM micrographs (Figure 2) and the narrowing of the size distribution (Figure 3), beneficial to tensile properties enhancement.

Concerning the samples prepared by FDM, as we can observe in Figure 8b, FDM printed samples show a brittle mechanical behavior, including PLA80-J2 and PLA80-J3 blends that exhibited a ductile behavior when processed by injection molding. As observed for injected samples, maximal stress tends to increase with increasing Joncryl content, to reach a maximum of 58.8 MPa for PLA80-J2 (Table S3). In comparison to the neat blend, Young modulus values are quite similar, except for PLA80-J2 and PLA80-J3 exhibiting a modulus higher than $3000 \mathrm{MPa}$.

If we compare FDM printed samples tensile properties to the ones of injected samples, FDM process can allow more rigid samples to be obtained, that means higher Young's moduli, especially at high Joncryl content (Figure 10). This can be ascribed to the aspect ratio of PA11 elongated dispersed 
phases, more important for printed samples in comparison to this for injected dog bone shaped samples (Figure 7 and Figure S2).

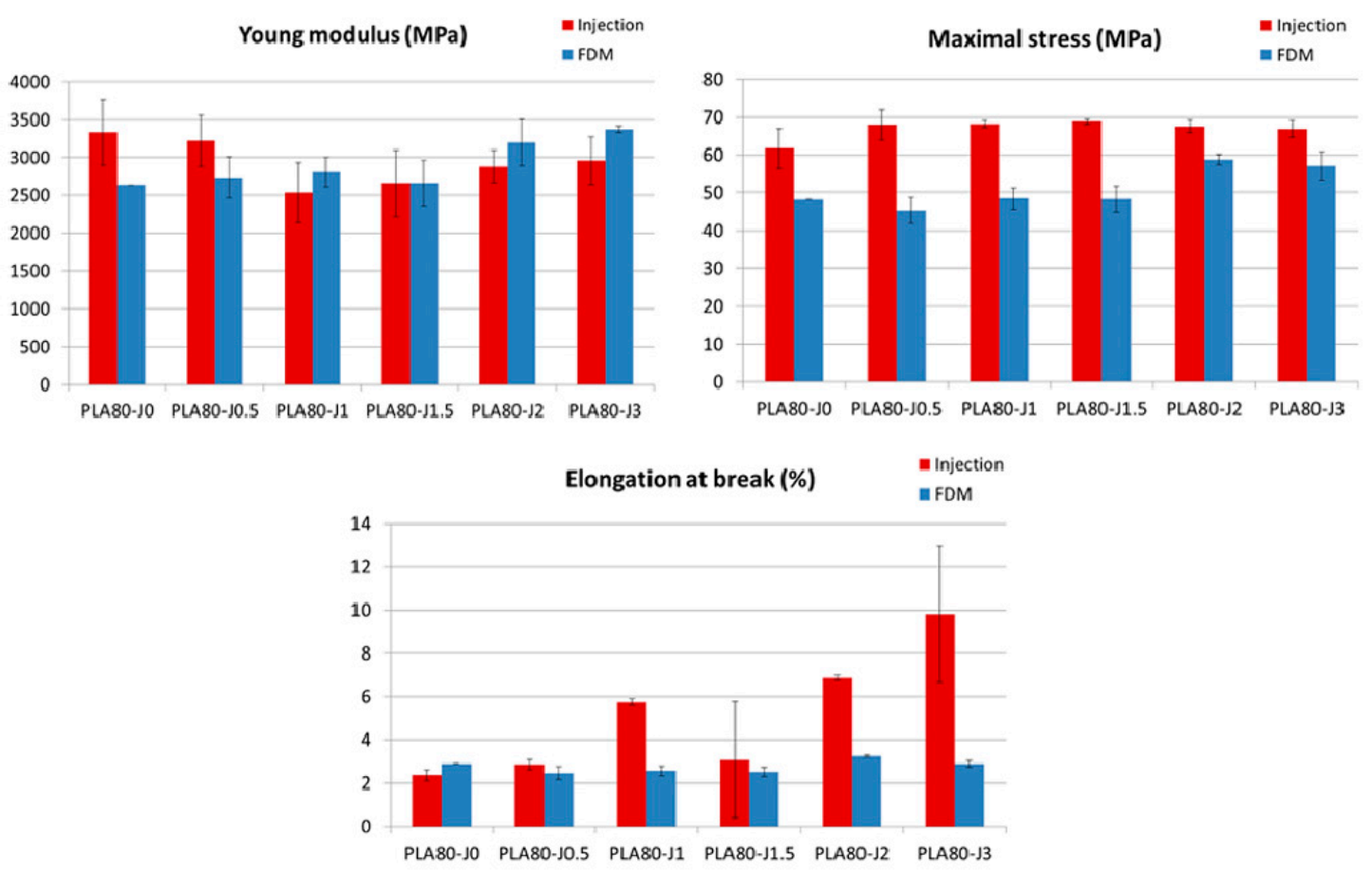

Figure 10. Injected versus FDM printed samples mechanical properties.

Nevertheless, it can be mainly noticed that FDM printed samples are more brittle compared to injected ones, since maximal stress and elongation at break are lower.

Two parameters related to FDM process can be pointed out to explain this difference: the lack of adhesion between deposited filaments and the porosity. FDM consists in the deposit of melted polymer flow on a support as aligned threads, that requires enough adhesion between deposited threads in a same layer or between the subsequent layers.

In the FDM process, melted filaments are extruded through a circular nozzle and deposited threads are circular, leading to trapped air between them, even if a partial merging and compression ensure cohesion between them. As a result, voids appear and represent potential cracking areas under mechanical stress.

Both parameters are involved in the cavitation process, leading to the material's failure. To determine to which extent these parameters affect tensile properties of printed samples, their morphology after the tensile test was observed and their porosity was determined.

\subsubsection{Printed Samples Morphology and Porosity}

After the tensile test, fracture surface morphology of FDM printed dog bone shaped samples varies as a function of Joncryl content, as observed for injected samples (Figure 9). Elongation of PA11 dispersed phases was observed, all the more important since Joncryl content is high (Figure 11). Such observations suggest that adhesion between polymers in the blend would be high enough to ensure a good mechanical transfer leading to enhanced mechanical properties.

Nevertheless, the experimental results do not support these assumptions. Hence, the lack of adhesion between the deposited threads and the existence of porosity between them seem to govern the mechanical behavior and can account for the brittleness of the printed samples in comparison with the injected ones. 


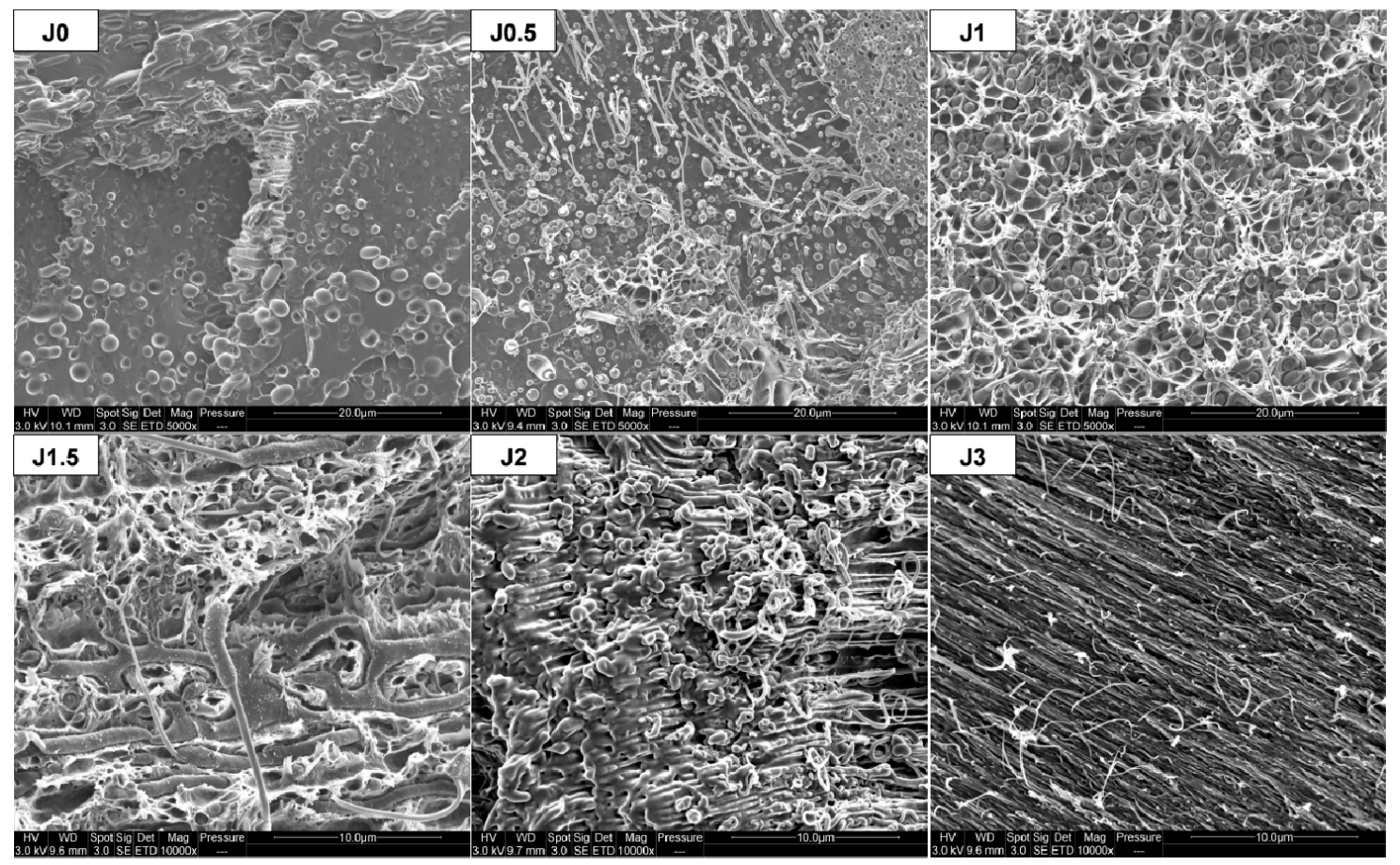

Figure 11. SEM observations of tensile fracture surface for printed samples.

Table 3 summarizes values obtained for porosity and absolute density of FDM printed samples. It can be noticed that samples have a similar absolute density and their porosity is quite important, higher to $10 \%$ on the whole. The highest porosities were measured for specimens with Joncryl content between $0.5 \%$ and $1.5 \%$. As shown Figure 12, there is a good correlation between porosity and mechanical properties. Indeed, these compositions have the poorest mechanical properties compared to other samples. Several hypotheses can be proposed to explain why porosity is higher for these samples compared to the other compositions.


Elongation at Break (\%)



Figure 12. Mechanical properties as a function of porosity for FDM printed samples. 
Table 3. Values obtained for porosity and absolute density of FDM printed samples.

\begin{tabular}{crccccc}
\hline Samples & \multicolumn{3}{c}{ Porosity (\%) } & \multicolumn{2}{c}{ Absolute Density $\mathbf{( g / \mathbf { c m } ^ { \mathbf { 3 } } )}$} \\
\hline PLA80-J0 & 9.91 & \pm & 0.29 & 1.1981 & \pm & 0.0007 \\
PLA80-J0.5 & 16.66 & \pm & 2.61 & 1.1986 & \pm & 0.0033 \\
PLA80-J1 & 19.93 & \pm & 0.60 & 1.2006 & \pm & 0.0015 \\
PLA80-J1.5 & 17.19 & \pm & 6.48 & 1.2026 & \pm & 0.0003 \\
PLA80-J2 & 7.47 & \pm & 4.90 & 1.1974 & \pm & 0.0007 \\
PLA80-J3 & 12.86 & \pm & 0.37 & 1.1945 & \pm & 0.0057 \\
\hline
\end{tabular}

First, viscosity of melted polymer during the FDM process could affect the deposition features of extruded thread. If the melted polymer is too viscous, the extruded thread will undergo few deformations and is unable to merge easily with the adjacent deposited thread, which creates voids. On the contrary, if melted polymer is less viscous, less air will be trapped, because the extruded thread will spread and could merge easily with the adjacent deposited thread.

Another parameter that can explain porosity development is the crystallization process and the crystallization rate of melted deposited polymer. If polymer has a fast crystallization and a high crystallinity after cooling, it will entail a shrinking of the deposited thread, which couldn't easily merge with the adjacent deposited thread and will create pores.

Further investigations would be necessary to determine the influence of these parameters.

\section{Conclusions}

Incorporation of Joncryl, a multifunctionalized epoxide, into a PLA/PA11 80/20 blend greatly improved properties of such a polymer blend, depending on its content. Studies of the morphological, thermal, rheological and mechanical properties of blends revealed that Joncryl acted as a compatibilizer. A reduction in PA11 dispersed phases diameter was observed, indicating compatibilization through coalescence suppression. Regarding the emulsification curve, saturation occured at $1.0 \mathrm{wt} \%$ of Joncryl.

PLA matrix cold crystallization changes in the compatibilized blends highlighted extension and branching reactions on PLA chains modified by Joncryl. The extent of such reactions is enhanced with increasing Joncryl content. Rheological and mechanical properties followed the same trend.

Complex viscosity of blends during frequency sweep tests increased from 0 to $1.5 \mathrm{wt} \%$ of Joncryl. Such an increase, mostly pronounced at low frequency, is assigned to an interfacial reaction between PLA and PA11 with Joncryl, as coupling agent. At $3 \mathrm{wt} \%$ of Joncryl, a slight reduction of complex viscosity was observed, that revealed the presence of an excess of Joncryl in the PLA matrix that didn't react. Tensile tests showed an enhancement of ultimate mechanical properties (maximal stress and elongation at break), especially for blends containing 2 and $3 \mathrm{wt} \%$ of Joncryl exhibiting a ductile behavior. This results from an improved interfacial adhesion through reactive compatibilization with Joncryl, as proved by SEM observations of tensile fracture surfaces. As a matter of fact, tensile tests show an elongation of PA11 ductile dispersed phases. Moreover, at high Joncryl content, the PLA matrix could be stretched with PA11 dispersed phases thanks to a high enough interfacial adhesion.

Preparation of compatibilized blends by FDM process led to a significant elongation of PA11 dispersed phases in FDM filaments and dog bone shaped specimens. Occurrence of such morphology was observed for Joncryl content from 1 to $2 \mathrm{wt} \%$. The aspect ratio of PA11 dispersed phases increases with Joncryl content. Despite this specific morphology, a priori beneficial to better tensile properties, FDM printed samples were more brittle compared to injected ones. Their maximal stress and elongation at break were lower. It is nevertheless interesting to note that higher Young's moduli could be obtained with FDM samples at 2 and $3 \mathrm{wt} \%$ of Joncryl, probably as a result of highly elongated PA11 dispersed phases. FDM printed samples' brittleness can be explained mainly by a lack of adhesion and porosity between deposited extruded threads during FDM process.

Supplementary Materials: The following are available online at http:/ /www.mdpi.com/1996-1944/12/3/485/s1, Figure S1: SEM observations of twin-screw extruded threads samples in longitudinal direction, Figure S2: SEM 
observations MEB of injected dog bone shaped samples, Table S1: Diameters of PA11 dispersed phases extracted from PLA80-Jx blends, Table S2: Mechanical properties of injected neat polymers and PLA80-Jx blends, Table S3: Mechanical properties of FDM printed PLA80-Jx blends.

Author Contributions: Investigation, D.R.; Writing-Original Draft Preparation, D.R.; Writing—Review \& Editing D.R., A.-S.C.-B., A.T. and J.-M.L.-C.; Visualization, D.R., A.-S.C.-B. and A.T.; Supervision, J.-M.L.-C.

Funding: This research received no external funding.

Acknowledgments: We gratefully thank Benjamin Gallard \& Sylvain Buonomo for their assistance in FDM filament preparation, and Arnaud Regazzi for his support in FDM processing parameters values selection.

Conflicts of Interest: The authors declare no conflict of interest.

\section{References}

1. Anderson, K.S.; Hillmyer, M.A. The influence of block copolymer microstructure on the toughness of compatibilized polylactide/polyethylene blends. Polymer (Guildf) 2004, 45, 8809-8823. [CrossRef]

2. Kim, Y.F.; Choi, C.N.; Kim, Y.D.; Lee, K.Y.; Lee, M.S. Compatibilization of immiscible poly(L-lactide) and low density polyethylene blends. Fibers Polym. 2004, 5, 270-274. [CrossRef]

3. Choudhary, P.; Mohanty, S.; Kayak, S.K.; Unnikrishnan, L. Poly(L-lactide)/Polypropylene Blends: Evaluation of Mechanical, Thermal, and Morphological Characteristics. J. Appl. Polym. Sci. 2011, 121, 3223-3237. [CrossRef]

4. Han, J.-J.; Huang, H.-X. Preparation and characterization of biodegradable polylactide/thermoplastic polyurethane elastomer blends. J. Appl. Polym. Sci. 2011, 120, 3217-3223. [CrossRef]

5. Broz, M.E.; VanderHart, D.L.; Washburn, N.R. Structure and mechanical properties of poly(D,L-lactic acid)/poly( $\varepsilon$-caprolactone) blends. Biomaterials 2003, 24, 4181-4190. [CrossRef]

6. Yeh, J.-T.; Tsou, C.-H.; Huang, C.-Y.; Chen, K.-N.; Wu, C.-S.; Chai, W.-L. Compatible and crystallization properties of poly(lactic acid)/poly(butylene adipate-co-terephthalate) blends. J. Appl. Polym. Sci. 2009, 116, 680-687. [CrossRef]

7. Chen, G.X.; Kim, H.S.; Kim, E.S.; Yoon, J.S. Compatibilization-like effect of reactive organoclay on the poly(l-lactide)/poly(butylene succinate) blends. Polymer (Guildf) 2005, 46, 11829-11836. [CrossRef]

8. Deng, Y.; Thomas, N.L. Blending poly(butylene succinate) with poly(lactic acid): Ductility and phase inversion effects. Eur. Polym. J. 2015, 71, 534-546. [CrossRef]

9. Signori, F.; Coltelli, M.-B.; Bronco, S. Thermal degradation of poly(lactic acid) (PLA) and poly(butylene adipate-co-terephthalate) (PBAT) and their blends upon melt processing. Polym. Degrad. Stab. 2009, 94, 74-82. [CrossRef]

10. Koning, C.; Van Dui, M.; Pagnoulle, C.; Jerome, R. Strategies for Compatibilization of Polymer Blends. Prog. Polym. Sci. 1998, 23, 707-757. [CrossRef]

11. Pillon, L.Z.; Utracki, L.A. Compatibilization of polyester/polyamide blends via catalytic ester-amide interchange reaction. Polym. Eng. Sci. 1984, 24, 1300-1305. [CrossRef]

12. Feng, F.; Ye, L. Structure and Property of Polylactide/Polyamide Blends. J. Macromol. Sci. Part B 2010, 49, 1117-1127. [CrossRef]

13. Meshchankina, M.Y.; Kuznetsova, Y.A.; Shcherbina, M.A.; Chvalun, S.N. Biodegradable blends obtained via reactive blending of polylactide and polyamide-6. Polym. Sci. Ser. B 2016, 58, 214-225. [CrossRef]

14. Utracki, L.A.; Catani, A.M.; Bata, G.L.; Kamal, M.R.; Tan, V. Melt rheology of blends of semicrystalline polymers. I. Degradation and viscosity of poly(ethylene terephthalate)-polyamide-6,6 mixtures. J. Appl. Polym. Sci. 1982, 27, 1913-1931. [CrossRef]

15. Retolaza, A.; Eguiazábal, J.I.; Nazábal, J. Structure and mechanical properties of polyamide-6,6/poly(ethylene terephthalate) blends. Polym. Eng. Sci. 2004, 44, 1405-1413. [CrossRef]

16. Stoclet, G.; Seguela, R.; Lefebvre, J.-M. Morphology, thermal behavior and mechanical properties of binary blends of compatible biosourced polymers: Polylactide/polyamide11. Polymer (Guildf) 2011, 52, 1417-1425. [CrossRef]

17. Patel, R.; Ruehle, D.A.; Dorgan, J.R.; Halley, P.; Martin, D. Biorenewable blends of polyamide-11 and polylactide. Polym. Eng. Sci. 2014, 54, 1523-1532. [CrossRef]

18. Heshmati, V.; Zolali, A.M.; Favis, B.D. Morphology development in poly (lactic acid)/polyamide11 biobased blends: Chain mobility and interfacial interactions. Polymer (United Kingdom) 2017, 120, 197-208. [CrossRef] 
19. Gug, J.; Sobkowicz, M.J. Improvement of the mechanical behavior of bioplastic poly(lactic acid)/polyamide blends by reactive compatibilization. J. Appl. Polym. Sci. 2016, 43350, 1-12. [CrossRef]

20. Dong, W.; Cao, X.; Li, Y. High-performance biosourced poly(lactic acid)/polyamide 11 blends with controlled salami structure. Polym. Int. 2013, 63, 1094-1100. [CrossRef]

21. Walha, F.; Lamnawar, K.; Maazouz, A.; Jaziri, M. Rheological, Morphological and Mechanical Studies of Sustainably Sourced Polymer Blends Based on Poly(Lactic Acid) and Polyamide 11. Polymers 2016, 8, 61. [CrossRef]

22. Zolali, A.M.; Favis, B.D. Compatibilization and Toughening of Cocontinuous PLA/PA11 Blend via Controlled Localization of Partially Wet Droplets at the Interface. Polymer (Guildf) 2017, 114, 277-288. [CrossRef]

23. Patrício, T.; Domingos, M.; Gloria, A.; D'Amora, U.; Coelho, J.F.; Bártolo, P.J. Fabrication and characterisation of PCL and PCL/PLA scaffolds for tissue engineering. Rapid Prototyp. J. 2014, 20, 145-156. [CrossRef]

24. Serra, T.; Ortiz-Hernandez, M.; Engel, E.; Planell, J.A.; Navarro, M. Relevance of PEG in PLA-based blends for tissue engineering 3D-printed scaffolds. Mater. Sci. Eng. C 2014, 38, 55-62. [CrossRef] [PubMed]

25. Chen, Q.; Mangadlao, J.D.; Wallat, J.; De Leon, A.; Pokorski, J.K.; Advincula, R.C. 3D Printing Biocompatible Polyurethane/Poly(lactic acid)/Graphene Oxide Nanocomposites: Anisotropic Properties. ACS Appl. Mater. Interfaces 2017, 9, 4015-4023. [CrossRef] [PubMed]

26. Findrik Balogová, A.; Hudák, R.; Tóth, T.; Schnitzer, M.; Feranc, J.; Bakoš, D.; Živčák, J. Determination of geometrical and viscoelastic properties of PLA/PHB samples made by additive manufacturing for urethral substitution. J. Biotechnol. 2018, 284, 123-130. [CrossRef] [PubMed]

27. Garcia, V.; Cailloux, J.; Santana, O.; Sanchez-Soto, M.; Carrasco, F.; Maspoch, M. Tailoring PLA/PA bioblends for 3D printing applications via the manufacturing of in situ microfibrillar composite filaments. In Proceedings of the Reunión del Grupo Especializado de Polímeros, Peñíscola, Spain, 15-19 June 2018.

28. Gonzalez Ausejo, J.; Rydz, J.; Musioł, M.; Sikorska, W.; Janeczek, H.; Sobota, M.; Włodarczyk, J.; Szeluga, U.; Hercog, A.; Kowalczuk, M. Three-dimensional printing of PLA and PLA/PHA dumbbell-shaped specimens of crisscross and transverse patterns as promising materials in emerging application areas: Prediction study. Polym. Degrad. Stab. 2018, 156, 100-110. [CrossRef]

29. Fischer, E.W.; Sterzel, H.J.; Wegner, G. Investigation of the structure of solution grown crystals of lactide copolymers by means of chemical reactions. Kolloid-Z. Z. Polym. 1973, 251, 980-990. [CrossRef]

30. Qingxin, Z.; Zhishen, M.; Siyang, L.; Zhang, H. Influence of Annealing on Structure of Nylon 11. Macromolecules 2000, 33, 5999-6005.

31. Rashmi, B.J.; Prashantha, K.; Lacrampe, M.; Krawczak, P. Toughening of poly(lactic acid) without sacrificing stiffness and strength by melt-blending with polyamide 11 and selective localization of halloysite nanotubes. Express Polym. Lett. 2015, 9, 721-735. [CrossRef]

32. Najafi, N.; Heuzey, M.C.; Carreau, P.J.; Wood-Adams, P.M. Control of thermal degradation of polylactide (PLA)-clay nanocomposites using chain extenders. Polym. Degrad. Stab. 2012, 97, 554-565. [CrossRef]

33. Najafi, N.; Heuzey, M.C.; Carreau, P.J. Crystallization behavior and morphology of polylactide and PLA/clay nanocomposites in the presence of chain extenders. Polym. Eng. Sci. 2013, 53, 1053-1064. [CrossRef]

34. Al-Itry, R.; Lamnawar, K.; Maazouz, A. Improvement of thermal stability, rheological and mechanical properties of PLA, PBAT and their blends by reactive extrusion with functionalized epoxy. Polym. Degrad. Stab. 2012, 97, 1898-1914. [CrossRef]

35. Wang, Y.; Fu, C.; Luo, Y.; Ruan, C.; Zhang, Y.; Fu, Y. Melt synthesis and characterization of poly(L-lactic acid) chain linked by multifunctional epoxy compound. J. Wuhan Univ. Technol. Sci. Ed. 2010, 25, 774-779. [CrossRef]

36. Moan, M.; Huitric, J.; Médéric, P.; Jarrin, J. Rheological properties and reactive compatibilization of immiscible polymer blends. J. Rheol. 2000, 44, 1227. [CrossRef]

37. Aravind, I.; Jose, S.; Ahn, K.H.; Thomas, S. Rheology and morphology of polytrimethylene terephthalate/ethylene propylene diene monomer blends in the presence and absence of a reactive compatibilizer. Polym. Eng. Sci. 2010, 50, 1945-1955. [CrossRef]

38. Nasrollah Gavgani, J.; Goharpey, F.; Velankar, S.; Foudazi, R. Suppressing droplet coalescence and aggregation in immiscible homopolymer blends by interfacially cross-linked compatibilizers. J. Rheol. 2018, 62, 1217-1231. [CrossRef]

39. Graebling, D.; Muller, R. Rheological behavior of polydimethylsiloxane/polyoxyethylene blends in the melt. Emulsion model of two viscoelastic liquids. J. Rheol. 1990, 34, 193-205. [CrossRef] 
40. Grace, H.P. Dispersion Phenomena in High Viscosity Immiscible Fluid Systems and Application of Static Mixers as Dispersion Devices in such Systems. Chem. Eng. Commun. 1982, 14, 225-277. [CrossRef]

41. Van Puyvelde, P.; Moldenaers, P. Rheology and Morphology Development in Immiscible Polymer Blends. Rheol. Rev. 2005, 2005, 101-145.

() 1

(C) 2019 by the authors. Licensee MDPI, Basel, Switzerland. This article is an open access article distributed under the terms and conditions of the Creative Commons Attribution (CC BY) license (http://creativecommons.org/licenses/by/4.0/). 